\title{
Prevalence of Chronic Kidney Disease and Associated factors among Patients with Kidney Problems Public Hospitals in Addis Ababa, Ethiopia
}

\section{Kore $\mathrm{C}^{1^{*}}$ and Yohannes $\mathrm{HM}^{2}$}

${ }^{1}$ Department of Public Health and Nursing, Rift Valley University, Addis Ababa, Ethiopia

${ }^{2}$ Department of Public Health, Addis Ababa University, Addis Ababa, Ethiopia

*Corresponding author: Cheru Kore, Department of Public Health and Nursing, Rift Valley University, Addis Ababa, Ethiopia, Tel: +251 912441527 ; E-mail: cherucuc@gmail.com

Received date: Jan 25, 2018; Accepted date: Feb 06, 2018; Published date: Feb 15, 2018

Copyright: (c) 2018, Kore C, et al. This is an open-access article distributed under the terms of the Creative Commons Attribution License, which permits unrestricted use, distribution, and reproduction in any medium, provided the original author and source are credited.

\begin{abstract}
Objective: The objective of this study to assess the prevalence and associated factors of chronic kidney disease among kidney problem patients attending public hospitals in Addis Ababa.

Method: This study was a hospital based quantitative cross-sectional study conducted among patients hospitalized in a nephrology clinic and OPD at public hospital Addis Ababa, Ethiopia. The sample was simple randomly selected based on standard sample size formula. The collected data was analyzed by using SPSS software: Versions 20 compute the variables by regression analysis such as bivariate and multivariate analysis was done.
\end{abstract}

Result: According to CKD EPI equation used to mobile application to calculate eGFR 66 (15.6\%) of participants have normal/stage 1, $49(11.6 \%)$ of participants have stage 2, 82(19.4\%) of the participants have stage 3 , 62 $(14.7 \%)$ stage 4 and $163(38.6 \%)$ stage 5 CKD respectively. Those patients who were in the age group of $>68$ were three times more likely ( $A O R 3.16(\mathrm{Cl} 1.36,7.35) ; P=0.07)$ to develop $C K D$ as compared to those who were under 18.

Conclusion and recommendation: This study identified a prevalence of CKD (38.6) by CKD EPI equations among Kidney disease patients that attend the public hospitals of Addis Ababa. Patients in Addis Ababa and out of Addis wait a lot of appointments because of shortage of dialysis service in public hospitals so the people lost their life exposed to high cost in the private dialysis center.

Keywords: Prevalence; CKD; Kidney problem; Public health; Proteinuria

\section{Introduction}

Kidney disease is a silent killer [1]. Kidney failure is also called endstage renal disease (ESRD) or Stage 5 Chronic Kidney Disease. When people have ESRD they need dialysis or a kidney transplant to survive [2]. Chronic Kidney Disease (CKD) is a worldwide public health problem [3]. The endemic occurrence of chronic kidney disease of unknown etiology $(\mathrm{CKDu})$ (sometimes referred to as chronic renal failure [CRF]) was first observed in the 1990s, and over the past 15 years the prevalence of the disease within certain geographical locations has increased dramatically [4]. The unique feature of the disease is that, it has no association with the well-known risk factors such as diabetes, hypertension or chronic glomerulonephritis [4]. The onset of the disease appears to be asymptomatic, and by the time patients seek treatment, the kidneys have reached a stage of irreversible damage (End Stage Renal Disease [ESRD] [4]. End-stage renal disease, also called established renal failure, is chronic kidney disease which has progressed so far that the patient's kidneys no longer function sufficiently and dialysis or transplantation become necessary to maintain life.
A retrospective, descriptive hospital cohort study carried out during the period 2001-2002, indicated that the number of persons with health issues seeking treatment at nephrology clinics in Anuradhapura and Kandy were increasing, and the majority was CKDu patients [4]. More recent investigations from community-based studies, report significantly higher rates (12.9\%) [5]. The disease appears to mainly affect the proximal tubules and the interstitium giving rise to characteristic, recognizable histopathological and clinical features [6]. Clinically, the disease is characterized by tubular proteinuria, usually ß2-microglobulinuria, and the absence of hypertension and edema [6]. The histological appearance of the disease reveals a tubule interstitial pathology that can commonly be observed in toxic nephropathies [6]. To date, there is no unequivocal evidence to recognize the possible environmental causative factors that could lead to nephro toxin being responsible for the disease [7]. Recent personal communications from scientists are pointing to episodic dehydration as a cause that could be a contributing factor for $\mathrm{CKDu}$ (farmers undergo episodic dehydration events due to their field activities) and the strong association with lifestyle habits that included smoking and the consumption of illicit liquor and micro albuminuria that is documented [8].

In this respect, the predominant causal factor(s) that have been suggested in the literature that may contribute to the development of the disease, include heavy metals (cadmium [Cd], arsenic [As] and 3 various nucleotides, including uranium [U]), elevated levels of fluoride 
Citation: Kore C, Yohannes HM (2018) Prevalence of Chronic Kidney Disease and Associated factors among Patients with Kidney Problems Public Hospitals in Addis Ababa, Ethiopia. J Kidney 4: 162. doi:10.4172/2472-1220.1000162

Page 2 of 5

(F) in groundwater, the specific composition of groundwater, aluminum (Al) and aflotoxins [9]. It is worth noting that this issue of chronic kidney disease (CKD) is not confined to Sri Lanka and that there are reports in the literature that describe similar clinical etiologies from India (Rao and Pereira 2007), Nicaragua [9], Costa Rica [10] and other Central American states [9]. The reports from Central America cite an increased risk of the disease among agricultural workers, in general and sugarcane workers in particular [10]. They have also noted that kidney disease decreases at higher altitudes [10]. Heavy workloads in hot climatic conditions often lead to chronic dehydration, which has emerged as a possible hypothesis in Central America [11].

\section{Materials and Methods}

\section{Study area}

According to the data obtained from Addis Ababa City Administration Health Bureau there are 11 public and 34 private hospitals in Addis Ababa, providing different services for the public. Three hospitals (Black Lion Specialized Hospital, St. Paul's Hospital Millennium Medical College and Zewditu Memorial Hospital) among the public hospitals were selected.

\section{Study design}

The study was a hospital based quantitative cross-sectional study.

\section{Study period}

This cross-sectional study was conducted for a period of two months from May to July, 2017.

\section{Population}

\section{Source of population}

All Patients with kidney disease was seen in and out patients in nephrology department at Black Lion Specialized Hospital, St. Paul's Hospital Millennium Medical College and Zewditu Memorial Hospitals.

\section{Study population}

Individuals were selected by the sampling technique in the nephrology department at Black Lion Specialized Hospital, St. Paul's Hospital Millennium Medical College and Zewditu Memorial Hospital during the study period.

\section{Ethical consideration}

This research project was approved by "Departmental Ethics and Research committee" of the Department of public Health, Collage of Health Science of Africa Medical College. The purpose of the study was explained to the study participants accordingly. Permission was obtained from each hospitals research center and nephrology clinic. Only subjects who gave informed consent were enrolled. Information was gathered from the study participants were kept confidential. The study results will be disseminated to health care providers to aid in patient care.

\section{Sample size determination}

The sample size was calculated based on single sample size estimation. The value of $\mathrm{p}$ is taken considering 95\% confidence interval, $5 \%$ margin of error and the value of $p$ taken was $50 \%$ because there is no study conducted related with CKD associated factors. The sample size is calculated using the following standard formula.

\author{
The sample size $n=z(\alpha 2)^{2} p(1-p) / d^{2}$ \\ Where $\mathrm{n}=$ Sample size \\ $\mathrm{Z}(\alpha 2)^{2}=$ At $95 \%$ confidence interval $\mathrm{Z}$ value $(\alpha=0.05)=1.96$ \\ $\mathrm{p}=$ Proportion of occurrence of the event to be studied \\ $\mathrm{d}=$ Margin of error at $(5 \%)(0.05)$ \\ $\mathrm{n}=(1.96)^{2} 0.5(1-0.5) /(0.05)^{2}$ \\ $\mathrm{n}=384$ \\ It was none respondents $10 \%$ \\ $384 \times 10 \%=38.4$ \\ $384+38.4=422.4 \sim 422$
}

\section{Sampling procedure}

The data was collected from study participants by interview method questionnaire and secondary data.

\section{Data management and quality control}

Data quality was ensured through use of WHO and CDC standardized questioners [12] to data collection materials, 21(5\%) pretested on non-selected area which was Korean Hospital of the questionnaires, after doing pre-test the questioner was maintained some problems such as the way question raised lab tests. Data collectors was identified, trained and informed to collect the data as the structured questionnaire before the starts of actual data collection from May 3-4, 2017 and intensive supervision during data collection by the principal investigator.

\section{Dependent (outcome) variables}

Chronic kidney disease

Independent variable: Socio demographic characteristics, history of diabetes, hypertension and cardiovascular disease, smoking habit and alcohol consumption, use of traditional medicine and over the counter medication (NSAID), history of kidney disease and status of kidney failure.

\section{Data processing and analysis}

Data entry and analysis was done using by SPSS statistical software version 20 . The odd ratio was calculated and put the dependent and independent variables in regression analysis to do binary and multivariate. Variables that show association $\mathrm{p}$ value $<0.2$ were selected for further analysis. In all cases P-value less than 0.05 was considered as statistically significant.

\section{Result}

The data was collected from 422 participants out of these 221 participants from SPHMMC (from OPD, medical wards, dialysis 
Citation: Kore C, Yohannes HM (2018) Prevalence of Chronic Kidney Disease and Associated factors among Patients with Kidney Problems Public Hospitals in Addis Ababa, Ethiopia. J Kidney 4: 162. doi:10.4172/2472-1220.1000162

Page 3 of 5

center and kidney transplant OPD), the rest 121 and 80 of the participants from BLSH and ZMH (OPD, dialysis and medical wards) respectively was collected from May, 2017 up to July, 2017.

The analysis of the demographic data found reveals the following results regarding age, sex, educational and marital status of the respondents: The mean (SD) age of the participants is 43.95 (1.68) years among the participants $210(49.8 \%)$ are between the age of 18 and 39 years, 107 (25.3\%) of the participants are between the age of 40 and 49 years. $105(24.9=\%)$ of the participants are 58 and above years. Two hundred thirty one (54.7\%) and one hundred ninety one $(45.3 \%)$ of the participants were males and females respectively. Concerning the educational background of the participants, 25(5.9\%) attended non formal education (illiterate) 119(28.2) attended primary education. One hundred fifty four (37.4\%) of the participants attended secondary education. $120(28.4 \%)$ of the participants attended College/University education level.

Regarding marital status of the respondents $90(21.3 \%)$ of them are single while two hundred eighty four $(67.3 \%)$ are married and $48(11.4 \%)$ are divorced and widowed/widower. From total population 184(43.6\%) participants have started dialysis. Out of one hundred eighty four $85(46.2 \%)$ of them started from the year one to three years back. $151(82.1 \%)$ of participants had three times dialysis schedule per week.

Almost all patients complained about long time of schedule to started dialysis before coming complicated of their kidney. 133(31.6\%) participants paid 400-500 ETH Birr per each dialysis in those public hospitals but those participants were paid 900-2000 ETH Birr per each dialysis in privet health institute before coming to those hospitals.

The history of diabetes, hypertension and cardiovascular disease of respondents among kidney patients in public hospital and crude and adjusted odd ratio of factors associated with CKD of respondents among kidney patients in public hospital, Addis Ababa has been shown below in Tables 1 and 2 .

\begin{tabular}{|c|c|c|}
\hline Variable & Yes $N(\%)$ & No $N(\%)$ \\
\hline Ever diagnosed for diabetic & $296(71.1 \%)$ & $126(29.9 \%)$ \\
\hline Confirmed & $77(18.2 \%)$ & $345(81.8 \%)$ \\
\hline Diagnosed for hypertension & $353(83.6 \%)$ & $69(16.4 \%)$ \\
\hline $\begin{array}{l}\text { If you say "yes" is that } \\
\text { confirmed }\end{array}$ & $253(60 \%)$ & $169(40 \%)$ \\
\hline $\begin{array}{l}\text { Have you diagnosed to } \\
\text { cardiovascular disease }\end{array}$ & $327(77.5 \%)$ & $95(22.5 \%)$ \\
\hline $\begin{array}{l}\text { If you say "yes" is that } \\
\text { confirmed }\end{array}$ & $82(19.4 \%)$ & $340(80.6 \%)$ \\
\hline $\begin{array}{l}\text { Do you have other chronic } \\
\text { diseases }\end{array}$ & $115(27.3 \%)$ & $303(71.7 \%)$ \\
\hline $\begin{array}{l}\text { If say yes which one the } \\
\text { following do you have }\end{array}$ & $\begin{array}{l}\text { Rheumatoid }=42(10.0 \%) \\
\text { Arthritis }=51(12.1 \%) \\
\text { Cholesterol }=8(1.9 \%) \\
\text { Liver }=34(8.1 \%) \\
\text { Others }=287(68 \%)\end{array}$ & \\
\hline
\end{tabular}

Table 1: History of diabetes, hypertension and cardiovascular disease of respondents among kidney patients in public hospital, Addis Ababa, $2017(n=422)$.

\begin{tabular}{|c|c|c|c|c|}
\hline Variables & Frequency & COR $(95 \% \mathrm{Cl})$ & AOR $(95 \% \mathrm{Cl})$ & P-value \\
\hline \multicolumn{4}{|l|}{ Age } & \\
\hline$<18$ & 73 & 1.00 & 1.00 & 1.00 \\
\hline $18-28$ & 137 & $1.29(0.95,1.75)$ & $1.46(1.05,2.03)$ & 0.02 \\
\hline $29-38$ & 50 & $1.62(1.08,2.43)$ & $1.50(0.95,2.36)$ & 0.08 \\
\hline $39-48$ & 57 & $2.11(1.44,3.09)$ & $2.40(1.59,3.65)$ & 0.01 \\
\hline 49-58 & 59 & $0.91(0.62,1.32)$ & $0.77(0.49,1.23)$ & 0.28 \\
\hline $59-68$ & 38 & $1.02(0.67,1.56)$ & $1.40(0.85,2.32)$ & 0.19 \\
\hline$>68$ & 8 & $2.89(1.29,6.45)$ & $3.16(1.36,7.35)$ & 0.07 \\
\hline \multicolumn{4}{|l|}{ Sex } & 0.01 \\
\hline Female & 191 & 1.00 & 1.00 & \\
\hline Male & 231 & $1.52(0.55,0.84)$ & $0.62(0.50,0.78)$ & \\
\hline \multicolumn{4}{|c|}{ History of HTN } & 0.08 \\
\hline No & 69 & 1.00 & & \\
\hline Yes & 353 & $0.78(0.60,1.02)$ & $1.26(0.97,1.64)$ & \\
\hline \multicolumn{4}{|c|}{ History of DM } & 0.03 \\
\hline No & 345 & 1.00 & 1.00 & \\
\hline Yes & 77 & $1.16(0.94,1.43)$ & $0.70(0.51,0.96)$ & \\
\hline \multicolumn{4}{|c|}{ History of cigarette smoking } & 0.75 \\
\hline No & 349 & 1.00 & 1.00 & \\
\hline Yes & 73 & $0.81(0.62,1.07)$ & $1.05(0.76,1.45)$ & \\
\hline \multicolumn{4}{|c|}{ History of non-steroid anti-inflammatory medicine } & 0.01 \\
\hline No & 170 & 1.00 & 1.00 & \\
\hline Yes & 252 & $0.65(0.53,0.81)$ & $0.48(0.37,0.61)$ & \\
\hline \multicolumn{4}{|c|}{ Habitual of prescribed medication } & 0.01 \\
\hline No & 75 & 1.00 & 1.00 & \\
\hline Yes & 347 & $1.73(1.32,2.27)$ & $2.22(1.65,2.98)$ & \\
\hline \multicolumn{4}{|c|}{ History of renal stone } & 0.79 \\
\hline No & 346 & 1.00 & 1.00 & \\
\hline Yes & 76 & $1.76(1.34,2.31)$ & $2.43(1.71,3.46)$ & \\
\hline
\end{tabular}

Table 2: Crude and adjusted odd ratio of factors associated with CKD of respondents among kidney patients in public hospital, Addis Ababa, $2017(n=422)$.

\section{Proportions of CKD}

According to CKD EPI equation used to mobile application to calculate eGFR $66(15.6 \%)$ of participants have normal/stage 1 , $49(11.6 \%)$ of participants have stage $2,82(19.4 \%)$ of the participants have stage $3,62(14.7 \%)$ stage 4 and $163(38.6 \%)$ stage 5 CKD respectively. This shows that the prevalence of CKD is higher for stage 5 and lower for stage 3 and stage 4 . 


\section{Discussion}

In those hospitals based quantitative cross sectional study, prevalence and associated factors of CKD among renal patients that attend public hospitals of Addis Ababa have been studied. CKD prevalence was greater among older persons and among persons with diabetes, cardiovascular disease and hypertension than among persons without these conditions, supporting previous findings. Mexican Americans and non-Hispanic blacks had greater prevalence of CKD than non-Hispanic whites. The large disparity in prevalence among those with stage $1 \mathrm{CKD}$ might be explained in part by racial/ethnic differences in micro albumin urea among non-Hispanic blacks and Mexican Americans [13-21]. By using CKD EPI equation, prevalence of CKD has been found to be $38.6 \%$ by the respective equations. Stage (1-2) prevalence of $\mathrm{CKD}$ is $27.2 \%,(15.6 \%$ and $11.6 \%)$ respectively. Whereas stage (3-4) prevalence of CKD is $34.1 \%$, (19.4\% and $14.7 \%)$ respectively by CKD EPI equation. Even though the difference is not statistically significant CKD EPI underestimates the prevalence compared to Cockcroft Gault. Among the 15.5\% participants with CKD by MDRD equation found in the study conducted in Canada $80 \%$ had eGFR 30-60 (Stage 3 CKD) which is comparable with this research finding but over $10 \%$ (1.6\% of total participants) [22] had ESRD which is $5.4 \%$ in this research finding by the same equation. The different between this study and the Canadian are the population and the methodology. That's why my study higher than those. The study done in Tanzania shows the prevalence of CKD among adult diabetic patients by Cockcroft Gault equation was 24.7\% [23-32]. The Tanzanian researcher focused on only prevalence of diabetic patients from CKD that's why higher different between this study and there. The research done in Ethiopia among diabetic patients by using similar equations with this study have found the prevalence of CKD to be $18.8 \%$ and $23.8 \%$ by MDRD and Cockcroft Gault equation respectively [9]. This study also focused in diabetic patient but I need to discuss because the populations are similar with this study. Not too many studies have reported results similar prevalence to this study because the studies found have determined the prevalence by using point prevalence whereas this research uses period prevalence. The CKD prevalence done among type 2 diabetics have found to be $27.9 \%$ [21] in Spain, while its prevalence found in this study is $10.79 \%$ by the MDRD equation which was the equation used in both studies. Regarding associated factors, different associated factors that have been presented in similar research were assessed to see whether they are 26 associated factors in these study population or not. Due to less number of respondents who smoke currently the result obtained regarding the prevalence of CKD among current smokers (0\%) may not be reliable. Older age, type 2 diabetes, family history of CKD, smoking habit, alcohol use, obesity, co-existence of hypertension have been assessed but no significant association was found. As it is the first study done in Addis Ababa, this research has its own limitations. Primarily, due to financial reasons the period prevalence of CKD is done by using the serum creatinine level of patients which is done recently among the tests done in the last five years. This in turn affects the reliability of the prevalence obtained as some patients who had a normal creatinine level before two or three years may have elevated or normal status had the test been done during the data collection [33-43]. The prevalence of CKD would have been much higher than the result obtained by this study, had the research used current level of creatinine. Third, some questions had not been filled by the respondents and that in turn affects the analysis and the result of the study [44-47]. Activities aimed at preventing CKD or its progression can decrease prevalence of the most severe form of CKD, stage 5 (i.e., End-Stage Renal Disease), which is associated with increased morbidity and mortality and diminished health-related quality of life [48]. Treatments such as control of high blood pressure in the early stages of CKD can prevent progression to end-stage renal disease [49].

\section{Acknowledgment}

I would like to thank god for doing all things in my life. I would like to express my deepest gratitude to my advisors Mr. Yohannes H/ Michael, Dr. Brhanu Worku and Dr Addisu Melke for their unreserved guidance and constructive comments throughout the whole progress of my research work. Also I would like to thank Mr. T/Haymanot Mezgebe (Bsc, MPH) Africa Medical College MPH coordinator, the whole staff of SPHMMC (St. Paulo's Millennium Medical College) specially IRB secretary Ms. Selamawit and Mebrhatu, the staff of BLSH and $\mathrm{ZMH}$ staffs they supported me by facilitating. I would like to give thanks to Mr. Hailu Taddese, Ms. Fasika Kore and Ms. Eyerusalem Abiot for their unreserved support. I would like to say thank you to all my study participants and I wish god bless them. Special thanks to Ms. Meaza Abrham to her effective support from the very beginning up to finalization of my work; god bless you. Last, but not the least I would like to thank all my family members and my friends.

\section{Conflict of Interest}

The authors have no conflict of interest to declare for this study.

\section{References}

1. National Kidney Foundation (2003) K/DOQI clinical practice guidelines for bone metabolism and disease in chronic kidney disease. Am J Kidney Dis 42: S1-S201.

2. National Chronic Kidney Disease fact sheet (2014).

3. Oluyombo R, Akinsola A, Ayodele O, Onayade A, Arogundade F, et al. (2011) Prevalence, risk factors and patterns of chronic kidney disease in a rural community in South West Nigeria. J Epidemiol Community Health 65: P1-271.

4. Wanigasuriya KP, Peiris-John RJ, Wickremasinghe R (2011) Chronic kidney disease of unknown etiology in Sri Lanka: Is cadmium a likely cause? BMC Nephrol 12: 32.

5. James MT, Hemmelgarn BR, Tonelli M (2010) Early recognition and prevention of chronic kidney disease. Lancet 375: 1296-1309.

6. Athuraliya NT, Abeysekera TD, Amerasinghe PH, Kumarasiri PV, Bandara P, et al. (2006) Towards understanding of chronic kidney disease of North central province. In proceedings of annual scientific sessions of Sri Lanka medical association.

7. Jayasekara JM, Dissanayake DM, Adhikari SB, Bandara P (2013) Geographical distribution of chronic kidney disease of unknown origin in north central region of Sri Lanka. Ceylon Med J 58: 6-10.

8. Athuraliya NT, Abeysekera TD, Amerasinghe PH, Kumarasiri PV, Bandara P, et al. (2011) Uncertain etiologies of proteinuria-chronic kidney disease in rural Sri Lanka. Kidney Int 80: 1212-1221.

9. Chandrajith R, Nanayakkara S, Itai K, Aturaliya NT, Dissanayake CB, et al. (2011) Chronic kidney diseases of uncertain etiology (CKDue) in Sri Lanka: Geographic distribution and environmental implications. Environ Geochem Health 33: 267-278.

10. Torres C, Aragón A, González M, López I, Jakobsson K, et al. (2010) Decreased kidney function of unknown cause in Nicaragua: A community-based survey. Am J Kidney Dis 55: 485-496.

11. Cerdas M (2005) Chronic kidney disease in Costa Rica. Kidney Int Suppl 97: S31-33.

12. School werth AC, Engelgau MM, Rufo KH, Vinicor F, Hostetter TH, et al. (2006) Chronic kidney disease: A public health problem that needs a public health action plan. Prev Chronic Dis 3: A57. 
13. Couser WG, Remuzzi G, Mendis S, Tonelli M (2011) The contribution of chronic kidney disease to the global burden of major non communicable diseases. Kidney Int 80: 1258-1270.

14. Jha V, Garcia-Garcia G, Iseki K, Li Z, Naicker S, et al. (2013) Chronic kidney disease: Global dimension and perspectives. Lancet 382: 260-272.

15. International Diabetes Federation Diabetes Atlas. Seventh edition (2015).

16. American Diabetes Association (2016) Classification and diagnosis of diabetes. Diabetes Care 39: S13-S22.

17. Naicker S (2010) Burden of end stage renal disease in Sub-Saharan Africa 74: S13-S16.

18. Yirsaw BD (2012) Chronic kidney disease in Sub-Saharan Africa: Hypothesis for research demand. Ann Afr Med 11: 119-120.

19. Temesgen F, Mehidi K, Tialhun Y (2014) Prevalence of chronic kidney disease and associated risk factors among diabetic patients in Southern Ethiopia. Am J Health Res 2: 216-221.

20. Jha V, Wang AY, Wang H (2012) The impact of chronic kidney disease identification in large countries: The burden of illness. Nephrol Dial Transplant 27: iii32-38.

21. Schieppati A, Remuzzi G (2005) Chronic kidney disease as a public health problem: Epidemiology, social and economic implications. Bergamo, Italy. Kidney International: S7-S10.

22. Abebe B, Habtamu T, Mekonnen T, Defard A, Getachew T, et al. (2015) Pattern and trend of medical admissions of patients of chronic noncommunicable diseases in selected hospitals in Addis Ababa. Am Scientific Res J Eng Tech Sci (AJRJETS). Online: 13: 34-48.

23. Getachew $\mathrm{T}$, Tadesse A (2006) Internal medicine: Lecture notes for health officers. Jimma University: Ethiopian public health training initiative.

24. Christiana O, Babawale T, Rotini W (2014) Chronic kidney disease: A ten year study of etiology and epidemiological trends in Lagos, Nigeria. British J Ren Med 19: 19-21.

25. Ponte B, Pruijm M, Marques-Vidal P, Martin PY, Burnier M, et al. (2013) Determinants and burden of chronic kidney disease in the populationbased CoLaus study: A cross-sectional analysis. Nephrol Dial Transplant 28: 2329-2339.

26. Farhad H, Farshad K, Amir A, Fereidoun A (2009) High prevalence of chronic kidney disease in Iran: A large population based study. BMC Public Health 9: 44.

27. Rothenbacher D, Klenk J, Denkinger M, Karakas M, Nikolaus T, et al. (2012) Prevalence and determinants of chronic kidney disease in community dwelling elderly by various estimating equations. BMC Public Health 12: 1-10.

28. Burkhalter F, Sannon H, Mayr M, Dickenmann M, Ernst S (2014) Prevalence and risk factors for chronic kidney disease in a rural region of Haiti. Swiss Med Wkly 144: w14067.

29. Austin G, Liam F, Cornelius J, Chernenko T, Cullen W, et al. (2014) Prevalence and variation of chronic kidney disease in the Irish health system: Initial findings from the national kidney disease surveillance program. BMC Nephrol 15: 1-12.

30. Saleem J, Rasool B, Tazean H (2014) Prevalence, determinants and management of chronic kidney disease in Karachi, Pakistan: A community based cross sectional study. BMC Nephrol 15: 90.

31. Antonio R, Josep G, Josep F, Diez-Espino J, Mundet-Tuduri X, et al. (2013) Prevalence of chronic kidney disease in patients with Type 2 diabetes in Spain: PERCEDIME2 Study. BMC Nephrol 14: 46.

32. Ronald F, Mariam N, Steward B (2012) Prevalence, determinants and comorbidities of chronic kidney disease among first nations adults with diabetes: Results from the CIRCLE study. BMC Nephrol 13: 57.
33. Bingcao W, Kelly B, Amy S, Kern DM, Tunceli O, et al. (2016) Understanding CKD among patients with T2DM: Prevalence, temporal trends, and treatment patterns 2007-2012. BMJ Open Diabetes Res Care 4: e000154.

34. Rachel J, Robert N, Janet H, Cheung CM, McElduff P, et al. (2006) The unrecognized prevalence of chronic kidney disease in diabetes. Nephrol Dial Transplant 21: 88-92.

35. Ohta M, Babazono T, Uchigata Y, Iwamoto Y (2010) Complications comparison of the prevalence of chronic kidney disease in Japanese patients with Type 1 and Type 2 diabetes. Diabet Med 27: 1017-1023.

36. Hill J, Cardwell R, Patterson C, Maxwell AP, Magee GM, et al. (2014) Chronic kidney disease and diabetes in the national health service: A cross-sectional survey of the UK national diabetes audit. Diabet Med 31: 448-454.

37. Earnest K, Eric P, Chantal V, Krzesinski JM, Pakasa NM, et al. (2009) High prevalence of undiagnosed chronic kidney disease among at-risk population in Kinshasa: The democratic republic of Congo. BMC Nephrol 10: 18.

38. Tandi E, Yandiswa Y, Megan A, Hassan MS, Kengne AP, et al. (2013) Chronic kidney disease in mixed ancestry South African populations: Prevalence, determinants and concordance between kidney function estimators. BMC Nephrol 14: 75.

39. Afolabi M, Abioye E, Arogundade F, Bello IS (2009) Prevalence of chronic kidney disease in a Nigerian family practice population. S Afr Fam Prac 51: 132-137.

40. Francois F, Diane T, Marie-Patrice H, Ngogang J, Kengne AP (2015) Prevalence and determinants of chronic kidney disease in rural and urban Cameroonians: A cross sectional study. BMC Nephrol 16: 117.

41. Francois F, Marie-Patrice H, Hermine T, Ashuntantang G, Fouda H, et al. (2015) Prevalence and risk factors of chronic kidney disease in urban adult Cameroonians according to three common estimators of the glomerular filtration rate: A cross-sectional study. BMC Nephrol 16: 96.

42. Mubarakali N, Samuel E, Andreas M, Kabangila R, Smart LR, et al. (2013) A study was done in Tanzania on the prevalence of chronic kidney disease in diabetic adult out patients. BMC Nephrol 14: 183.

43. Temesgen F, Mehidi K, Tilahun Y (2014) Chronic kidney disease and under diagnosis of renal insufficiency among diabetic patients attending a hospital in Southern Ethiopia. BMC Nephrol 15: 198.

44. Igor C, Vera S, Serijiu G, Suveica L, Popa S, et al. (2012) Prevalence of hypertension and diabetes and coexistence of chronic kidney disease and cardiovascular risk in the population of the republic of Moldova. Int J Hypertens: Page 8.

45. Gizaw R, Gebremedhin LT (2011) Implementing a balanced scorecard at St. Paul's Hospital, Addis Ababa, Ethiopia. Ministerial Leadership Initiative for Global Health.

46. Building synergies and advancing nephrology in all regions of the globe (2015): Page 6.

47. WHO (2003) The World Health Report, shaping the future.

48. Emerging public health problems in Ethiopia: Chronic noncommunicable disease (2012). Ethiopian public health association (EPHA), Addis Ababa, Ethiopia.

49. Levey AS, Coresh J, Balk E, Kausz AT, Levin A, et al. (2003) National kidney foundation practice guidelines for chronic kidney disease: Evaluation, classification and stratification. Ann Intern Med 139: 137-147. 